\title{
A contribuição do modelo da construcionalização e mudanças construcionais: reflexões em Português
}

\author{
Maria Maura Cezario (UFRJ/CNPq) ${ }^{1}$ \\ Karen Sampaio Braga Alonso (UFRJ) ${ }^{2}$
}

Resumo: Neste artigo, apresentaremos uma discussão acerca do modelo de estudo para as mudanças linguísticas denominado Construcionalização/mudanças construcionais proposto por Traugott e Trousdale (2013), explicitando como temos trabalhado com conceitos como construção, níveis da construção, mudanças construcionais, formação de novas construções, dentre outros. Tomaremos dois exemplos de pesquisas orientadas por nós, a pesquisa sobre usos da construção [Um monte de SN] e a pesquisa sobre usos de verbo com adjetivo adverbial com valor qualitativo $\left(\left[\mathrm{VA}_{\text {adv }}\right)\right]_{\text {Qualit.. }}{ }^{3}$ Concebemos que a gramática é formada por uma rede de construções conectadas entre si e que a formação de uma construção linguística se dá através da atuação de processos cognitivos do domínio geral em conjunto com a rotinização de certos usos, devido sobretudo à frequência alta de certas combinações de elementos linguísticos. Mostraremos que, no português atual, um monte é parte de uma construção [um monte de $\mathrm{SN}$ ] com valor quantitativo e que tem origem numa construção em que o sintagma preposional qualificava o substantivo monte; também ilustraremos a discussão com o caso da formação de expressões idiomáticas (construções lexicalizadas) criadas a partir da construção $\left(\left[\mathrm{VA}_{\text {adv }}\right)\right]_{\text {Qualit }}$.

Palavras-chaves: gramática como rede de construções; mudança linguística; formação de construções do português.

\section{Introdução}

O presente artigo tem como objetivo avaliar a abrangência e os limites do modelo teórico da construcionalização/mudanças construcionais (TRAUGOTT \& TROUSDALE, 2013), desenvolvido para dar conta da mudança linguística, a partir de sua aplicação em dados do português de diferentes naturezas. Para tanto, o presente texto se divide nas seguintes

\footnotetext{
${ }^{1}$ Professora Associada IV Departamento de Linguística e Filologia da UFRJ, atua na Pós-graduação de Linguística da UFRJ, fez Mestrado e Doutorado nessa instituição e pós-doutorado na Universidade de Edimburgo. É coordenadora do Grupo de Estudos Discurso e Gramática- Rio e autora de diversos artigos e capítulos de livros sobre Linguística Funcional Centrada no Uso. É pesquisadora do CNPq.

${ }^{2}$ Professora Adjunta IV do Departamento de Linguística e Filologia da UFRJ. É docente Programa de Pós-graduação em Linguística da UFRJ e do Mestrado Profissional em Letras da UFRJ (PROFLETRAS). Também é substituta Eventual do Diretor de Cultura e Extensão da Faculdade de Letras da UFRJ. Possui Mestrado e Doutorado em Linguística pela UFRJ e pósdoutorado na Universidade da Califórnia (Berkeley). É autora de artigos e capítulos de livros na área de Linguística Funcional Centrada no Uso.

${ }^{3}$ Agradecemos a colaboração de Júlia Langer, responsável pela pesquisa relativa à construção $\left(\left[\mathrm{VA}_{\mathrm{adv}}\right)\right]_{\text {Qualit. }}$ e a Caroline Fumaux, que estudou a formação da construção [um monte de SN]. Agradecemos à Professora Priscilla Mouta Marques pelas contribuições acerca da análise da construção ([VA $\left.\left.\mathrm{Vdv}_{\mathrm{av}}\right)\right]_{\text {Qualit. }}$
} 
etapas: (i) apresentação do modelo teórico dos referidos autores, entremeada por apreciação crítica; (ii) resultados de pesquisa empírica na área da mudança linguística com avaliação da abrangência e dos limites do modelo de Traugott \& Trousdale.

Traugott \& Trousdale (2013, p.1) concebem que existem dois tipos de mudanças: (a) as mudanças construcionais, que afetam ou o plano da forma ou o plano do conteúdo, como, por exemplo, as mudanças apenas fonológicas ou apenas de significado de uma dada estrutura; e (b) a construcionalização, que é o resultado de mudanças construcionais que acontecem nos dois planos afetando uma mesma estrutura da língua e dando origem, assim, a uma nova construção gramatical.

Na obra de Traugott \& Trousdale (2013), construcionalização ora é apresentada como processo, ora como resultado de processos de mudança. Nesse ponto, vale uma breve reflexão sobre o que estamos considerando quando olhamos para a mudança linguística.

De um lado, a língua, como sistema, encontra-se em constante transformação, e suas formas sofrem modificações que gradualmente se espalham pelas comunidades estratificadas de fala até que atinjam um dado grau de automatização que afete o sistema de forma mais geral e menos localizada. Sob essa perspectiva, de que o sistema muda de forma gradual e não abrupta, a construcionalização parece, sim, ser um processo de mudança em que uma dada sequência sintagmática, ao longo do tempo, passa a ter autonomia tanto na forma quanto no sentido e se torna uma construção. Nesse sentido também, a gramática é emergente, e o foco da análise recai sobre os processos de mudança a que as formas linguísticas se sujeitam e seu impacto na arquitetura gramatical de uma dada língua - isto é, na rede de pareamentos formasentido automatizados a que chamamos gramática. Aparentemente, do ponto de vista da gramática, a construcionalização é processo (assumindo que, embora não exclusivamente, a mudança gradual é a forma mais comum de mudança da língua) e produto (assumindo que a arquitetura gramatical de uma língua, ainda que emergente, comporta formas automatizadas relativamente estáveis).

Por outro lado, a observação empírica dos fatos linguísticos implica necessariamente um falante que observa o mundo à sua volta e busca representá-lo por meio de signos verbais. Sob essa ótica, construcionalização é a criação de novo nó na rede, portanto produto criado a partir de diferentes processos cognitivos de domínio geral. Nesse sentido, ela não pode ser um processo gradual de mudança, uma vez que o falante interpreta um sentido novo de uma 
estrutura linguística já existente, por exemplo, de maneira abrupta. É o efeito da disseminação das interpretações individuais dos falantes que pode vir a ser, com o tempo, automatizado por um dado estrato social (e não o processamento online do falante durante ato comunicativo em si).

Sob a ótica do falante, a construcionalização é a criação de um novo nó na sua rede de construções e, sendo assim, está diretamente ligada a processos cognitivos, como neoanálise, chunking, analogização e categorização. Como quem usa a língua age sobre ela, processos cognitivos podem levar a mudanças construcionais e, quando tais mudanças acontecem no plano da forma e do conteúdo, geram um novo pareamento simbólico e alteram a gramática (rede de construções). Esse novo pareamento, se não experienciado novamente, pode ser apagado da memória do falante e, portanto, ter afetado a rede apenas provisoriamente ou, se experienciado repetidas vezes, pode ser automatizado e passar a ser armazenado no constructicon $^{4}$, sendo, assim, psicologicamente real na mente do falante.

Uma teoria adequada à mudança linguística deveria dar conta dessas duas dimensões:

1. a dimensão discursivo-gramatical da mudança, que trata dos epifenômenos que afetam o plano da forma e/ou do conteúdo das estruturas de uma língua e da maneira como essas se comportam: (a) intra-sistemicamente, isto é, em competição com outras formas de função/ sentido semelhantes e (b) extralinguisticamente, na averiguação sobre se refletem, ou não, uma expansão gradual nos estratos de fala;

2. (ii) a dimensão cognitiva, que pretende dar conta do conhecimento de todo indivíduo que o faculta a adquirir uma dada língua, usando-a e modificando-a ao longo da vida.

O modelo teórico das mudanças construcionais/ construcionalização parece investir nessas duas dimensões, assumindo, de um lado, uma visão funcionalista de mudança na gramática, pois adota um caráter claramente construcionista baseado no uso; de outro, a abordagem dos modelos cognitivos de domínio geral, que defendem que não é um conhecimento especificamente linguístico que leva o indivíduo a ser capaz de falar/ interpretar uma língua, mas processos cognitivos de ordem mais geral, que dariam conta de

4Constructicon é o nome que se dá ao repositório mental de construções em rede. 
como o ser humano processa tanto o mundo linguístico quanto o mundo não-linguístico. Em outras palavras, não haveria uma diferença rígida entre conhecimento linguístico e conhecimento de mundo.

Neste artigo, discutiremos esses e outros pressupostos teórico-metodológicos, exemplificando com dados de pesquisa que desenvolvemos sobre a formação da construção [um monte de $\mathrm{SN}]$, como "Ele bebeu um monte de água" e $\left(\left[\mathrm{VA}_{\mathrm{adv}}\right)\right]_{\text {Qualit., }}$ como em "Meu coração bateu forte pela matéria Linguística".

\section{A rede construcional}

As diferentes vertentes construcionistas caracterizam-se embrionariamente por rechaçar a separação rígida entre léxico e gramática. Sobre essa separação, Goldberg (2013: p. 15) afirma que "essa ideia atende pelo nome de modelo dicionário-e-gramática, o qual é um modelo de conhecimento linguístico em que o conhecimento de vocabulário é claramente separado do modelo de conhecimento de regras gramaticais".

Num caminho oposto, as diferentes gramáticas de construções (Gramática de Construções Cognitiva, Gramática de Construções Radical, entre outras), por sua vez, se caracterizam por compartilhar certas premissas, conforme apontam Traugott \& Trousdale (2013:3):

(a) A unidade básica da gramática é a construção, a qual é um pareamento convencional de forma e sentido;

(b) a estrutura semântica é mapeada diretamente na estrutura sintática superficial, sem derivações;

(c) a língua, como outros sistemas cognitivos, é uma rede de nós e relações entre nós; as associações entre alguns desses nós tomam a forma de hierarquias por herança (relações taxonômicas capturando o grau em que as propriedades de construções de nível mais baixo são previsíveis a partir daquelas mais gerais);

(d) variação translinguística (ou dialetal) pode ser explicada de várias maneiras, incluindo processos cognitivos de domínio geral. 
Ainda segundo os autores (TRAUGOTT \& TROUSDALE, 2013, p. 3), todas as vertentes construcionistas enxergam a língua de forma "holística", de modo que não há um nível gramatical autônomo ou “central”. Diessel (2015, p. 2), tratando da visão construcionista de gramática, ressalta que "a estrutura linguística pode ser analisada em termos de signos complexos, isto é, construções, combinando um padrão estrutural com uma função ou significado particular" e que "todos os signos linguísticos (isto é, signos lexicais e signos gramaticais) estão conectados uns aos outros por vários tipos de relações; logo, que a gramática (ou língua, em geral) pode ser vista como uma rede dinâmica de signos interconectados".

Toda construção gramatical consiste em um pareamento forma-sentido, conforme podemos ver em Croft (2001, p. 18):

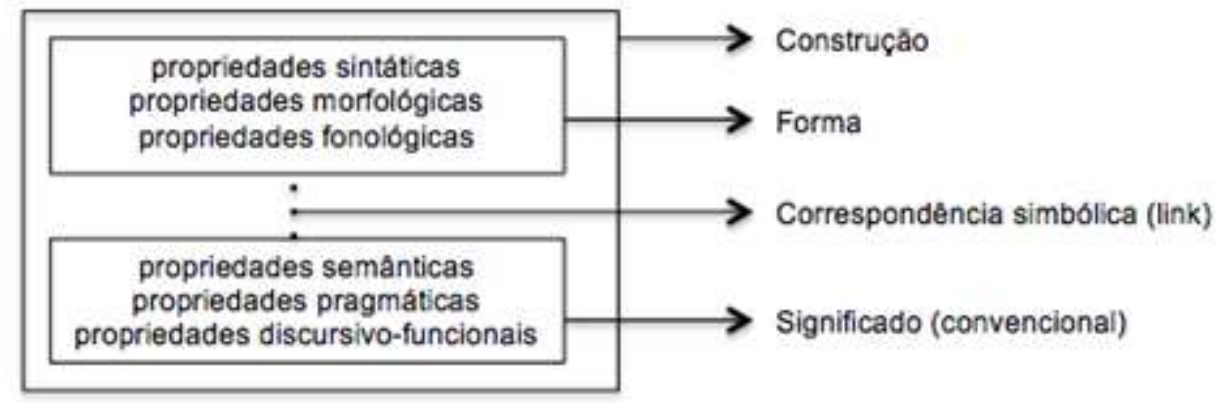

Figura 1: Propriedades da construção. Fonte: Croft, 2001:18.

A noção de construção em Croft (2001, p. 18) explicita, na própria definição, fatores de naturezas distintas, incluindo aspectos semânticos, pragmáticos e discursivo-funcionais, no plano do sentido, e sintáticos, morfológicos e fonológicos, em termos da forma. $\mathrm{O}$ autor, portanto, revela de forma bastante detalhada o conjunto de conhecimentos que o falante convencionaliza quando aprende uma construção gramatical. Assim, faz-se necessário, para se descrever fenômenos gramaticais de línguas naturais, levar em consideração os contextos de uso das construções gramaticais e suas propriedades em termos tanto de forma quanto de sentido. Ainda, de acordo com Goldberg (2006, p. 5), os pareamentos forma-sentido que se apresentam como as unidades gramaticais que compõem essa perspectiva teórica podem ser entendidos, basicamente, como "pareamentos aprendidos de forma com função semântica ou 
discursiva, incluindo morfemas ou palavras, idiomatismos, padrões sintagmáticos parcialmente preenchidos ou totalmente gerais".

Segundo Langacker (1987), quando se pensa em construção, leva-se em conta, pelo menos, três fatores distintos que afetam sua estrutura, a saber:

(i) generalidade, que se refere ao grau em que o esquema construcional reflete um padrão mais esquemático do que específico;

(ii) produtividade, que dá conta do grau em que o esquema construcional é acessível a sancionar novas ocorrências; e

(iii) composicionalidade, que trata do grau em que o sentido e a forma do todo são previsíveis por suas partes de acordo com o esquema sancionador.

A proposta do autor oferece parâmetros fundamentais para se pensar sincronicamente a língua, como também, conforme mostram Traugott \& Trousdale (2013), a mudança linguística. Para isso, os autores postulam a necessidade de estudar a generalidade (ou esquematicidade), produtividade e composicionalidade para o entendimento da forma como construções são afetadas e sofrem mudanças ao longo de um dado período de tempo. De forma geral, construções podem ser totalmente esquemáticas (como é o caso de uma construção do tipo de SN SNgen) semi-esquemáticas (caso de [Adj mente]) ou totalmente preenchidas (como o que se vê em tirar água do joelho). Construções também podem apresentar graus distintos de produtividade, o que poderá ser verificado em termos de análises que levam em conta frequências type e token de uma dada construção. Em relação à composicionalidade, uma sequência sintagmática pode apresentar maior ou menor grau de previsibilidade de seu sentido total a partir da soma do significado de cada uma de suas partes componentes.

As diferentes vertentes do modelo da Gramática de Construções assumem que as construções de uma dada língua se organizam em um modelo de rede. Para ilustrar essa proposta, Diessel (2015) apresenta a figura a seguir, a qual representa uma rede de relações lexicais, afirmando que " se a estrutura linguística consiste de signos, é uma hipótese plausível que a gramática seja organizada da mesma forma que o léxico mental, o qual é comumente caracterizado como uma rede de relações de signos ou símbolos" (DIESSEL, 
2015: p. 6). Nesse âmbito, atente-se para o fato de que o autor faz uso de uma noção de signo estendido:

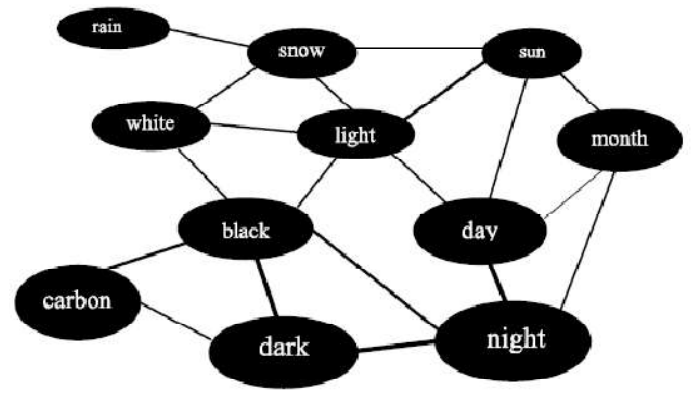

Figura 2: Rede lexical. Fonte: Diessel, 2015:6.

Essa figura ilustra a premissa de que as unidades simbólicas estão interconectadas e que a compreensão de uma se dá a partir da relação que essa estabelece com as demais unidades dentro da rede. Marques, Alonso e Pinheiro (2017: p. 1150-1151), em artigo que visa relacionar as reflexões gramaticais apresentadas no Curso de Linguística Geral de Ferdinand Saussure com as abordagens construcionistas da gramática, afirmam que:

\begin{abstract}
A ideia de rede, tal como desenhada no modelo da Gramáticade Construções, parece dar conta tanto de relações do tipo associativas, bem como das relações de combinação do tipo daquelas descritas no eixo sintagmático (para mais detalhes, ver DIESSEL, 2015), que se mostram imprecisas no Curso, uma vez que a abordagem lexicalistal de Saussure se baseia sobretudo na palavra. Vantajosamente, a noção de construção abarca pareamentos de forma e sentido que variam de mais lexical a mais esquemáticos, de mais composicionais a mais idiomáticos, incorporando, portanto, os exemplos clássicos de signo saussuriano (palavras), os exemplos acrescentados à noção de signo (sequências de duas ou mais palavras que formam um todo) e também aqueles que ficam de fora da língua (formações sintagmáticas complexas e produtivas).
\end{abstract}

A partir daí, pesquisadores da área vêm procurando descrever a natureza dessas relações, como o que pode ser visto em Goldberg (1995) e Diessel (2015), por exemplo. Dentre as relações de que trata Diessel, estão as taxonômicas, que preveem uma relação hierárquica, vertical, entre construções mais esquemáticas e construções menos esquemáticas 
(para Goldberg, relações de herança por instanciação também refletem conexões entre construções mais e menos gerais). Sobre isso, é importante ressaltar que o modelo entende que, no constructicon (inventário estruturado de unidades simbólicas), as construções são armazenadas em todos os níveis, redundantemente - ou seja, a partir de uma construção do tipo um monte de $S N$, seria possível (e, portanto, demonstrável a partir de análises de frequência conjugadas com testes psicolinguísticos) que o falante armazene redundantemente no constructicon unidades como um monte de $S N$, um monte, um monte de, um SN de SN, SN de $S N$, etc. Assume-se, portanto, um modelo que coloca mais peso na estocagem de unidades e menos peso no processamento. Atrelado a isso, entende-se também que, uma vez que a memória é rica, o falante armazena detalhes da sua experiência com o mundo e também com a língua.

Diessel (2015) ainda define outros tipos de relações entre construções, a saber: (i) relações horizontais, que dão conta de relações entre construções de mesmo nível de abstração e, por estarem associadas na rede, o uso de uma propicia o uso da outra; (ii) relações sintáticas, em que se assume, com base em Croft (2001: p. 45-46), que "as construções, e não as categorias e relações, são as unidades básicas, primitivas, da representação sintática”. Nas relações sintáticas, assim "como em construtos e construções, categorias e construções estão relacionadas umas com as outras por relações taxonômicas que são parte do nosso conhecimento gramatical (DIESSEL, 2015, p. 14); e relações entre construções e lexemas. Nesse caso, de acordo com o autor (DIESSEL, 2015, p.15), “a estrutura linguística é fundamentalmente baseada nas experiências do falante com expressões linguísticas concretas".

Esses quatro tipos de relações (fundamentados na concepção da gramática como uma rede estruturada de pareamentos de forma e sentido) são importantes para se pensar na relação de herança entre construções (especialmente vinculada às relações taxonômicas e sintáticas), bem como nas extensões de sentido que as construções apresentam (essencialmente vinculada às relações horizontais e àquelas entre lexemas e construções).

Um exemplo de relações taxonômicas entre construções pode ser visto na figura a seguir, retirada de Croft (2001:p. 23). 

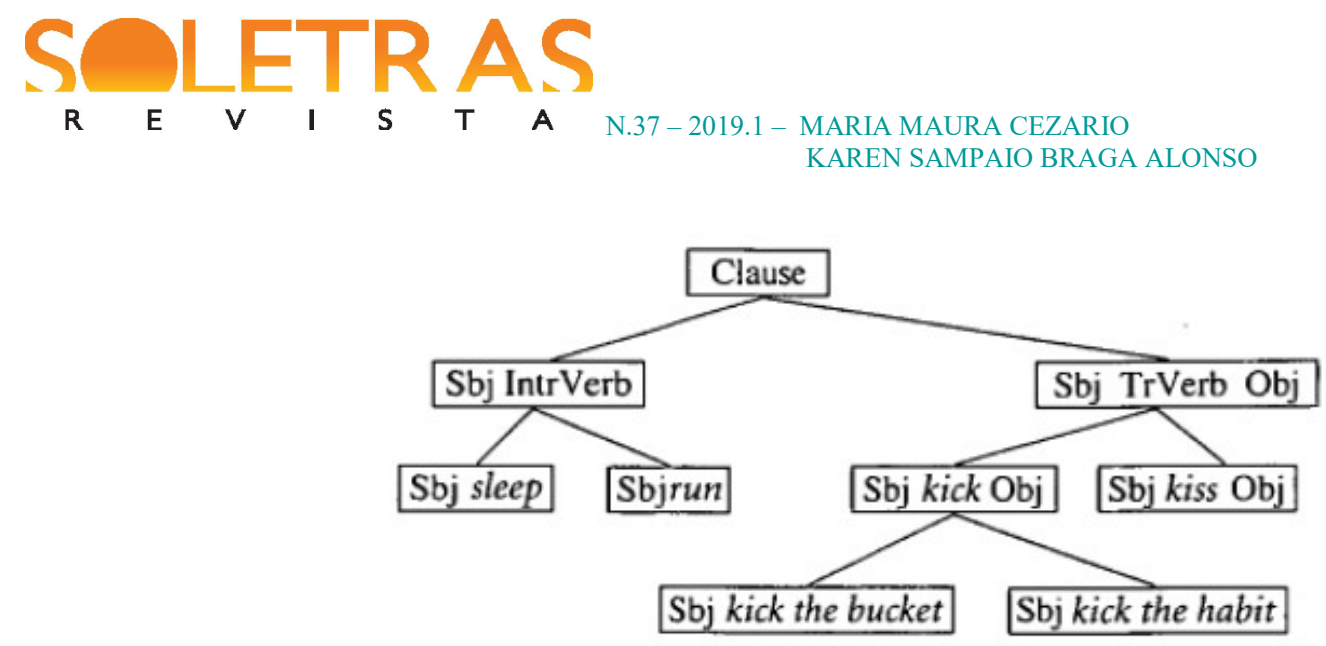

Figura 3: Hierarquia taxonômica de tipos de cláusulas. Fonte: Croft, 2001: p. 23

Nesse esquema, o autor ilustra relações hierárquicas entre construções mais gerais e construções mais baixas na rede, as quais apresentam partes lexicalmente especificadas. Partindo daí, o surgimento de uma nova construção na língua pode se dar nos diferentes níveis de esquematicidade - nas palavras de Traugott \& Trousdale (2013), no nível da microconstrução, do subesquema ou do esquema. Uma nova construção pode, por exemplo, surgir de uma instância de uso de uma dada construção mais abstrata, como é o caso do idiomatismo "chutar o balde", que nasce da instanciação de uma construção já existente (SVO), mas passa a ser armazenado de forma autônoma, ou seja, passa a ser acessada diretamente pelo falante. Assim, chutar o balde, como expressão idiomática, já é outro nó na rede, tem representação na memória como uma unidade distinta de SVO. Chutar o balde tem uma relação de instanciação com a construção mais geral SVO, mas se construcionaliza a partir de cristalizações de uso, ou seja, o que antes era uma instância da construção passa a ser um todo indivisível, com sentido idiossincrático, tendo, portanto, sua forma e seu significado afetados.

Bybee (2010, p. 63), ao tratar de combinações convencionalizadas do tipo ponerse nervioso, quedarse solo, quedarsesorprendido etc., afirma que:

No nível das construções, a evidência também aponta para a importância de combinações prévias na produção de novas combinações, com base agora no sentido. Bybee e Eddington (2006) estudam verbos de tornar-se em vários corpora grandes do espanhol para determinar quais verbos ocorrem com quais adjetivos. Esse caso é mais um em que a tentativa de se estabelecer regras ou a busca insistente pelas propriedades relevantes dos verbos e adjetivos não tem tido sucesso. Há uma série de verbos do espanhol que são 


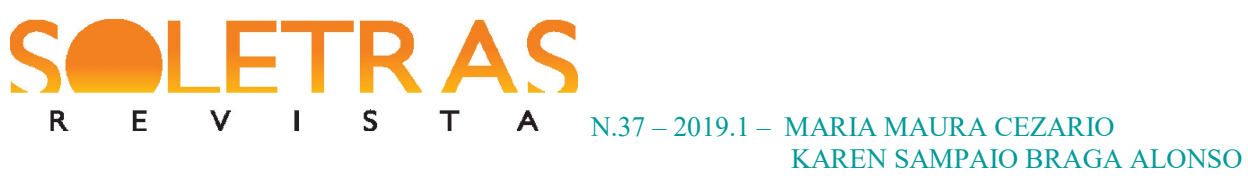

usados com adjetivos ou sintagmas preposicionais para indicar 'a entrada em um estado'.

Os dados apresentados por Bybee (2010) evidenciam que pareamentos convencionalizados de forma e sentido se desenvolvem a partir do uso da língua, em que se considera que uma combinação mais frequente é tomada de forma central e serve para, analogicamente, recrutar novas combinações com itens semanticamente aproximados.

Um fato crucial para o modelo da construcionalização é o entendimento de que o uso da língua estrutura a gramática e é, também, estruturante (BYBEE, 2010). Uma vez formado novo pareamento, ou seja, nova construção, outras construções podem ser formadas e, a partir daí, podem ser representadas em uma construção mais alta na rede. A construção mais geral, por sua vez, via força coercitiva, também afeta o modo como interpretamos e categorizamos as sequências de uso na língua. Pode ocorrer também que um uso, por alta frequência, seja armazenado como microconstrução e se desgarre da rede à qual se vinculava incialmente, ou seja, passe a ser acessado diretamente, como se viu em chutar o balde.

\section{O caso de [um monte de $\mathrm{SN}]$}

Considerando o que foi dito anteriormente, assume-se que o modelo construcionista da gramática (GOLDBERG, 2006; CROFT, 2001; BYBEE, 2010), na vertente em que se conforma aos pressupostos teórico-metodológicos dos Modelos Baseados no Uso (BARLOW \& KEMMER, 2000), prevê que as estruturas linguísticas reconhecidas como construções gramaticais sejam fruto de cristalizações geradas a partir de tipos (types) de exemplares (BYBEE, 2006) de alta frequência no uso da língua. Ou seja, leva-se em conta também uma perspectiva bottom-up para a emergência das construções gramaticais que comporão a rede.

\footnotetext{
${ }^{5}$ At the level of constructions the evidence also points to the importance of prior combinations in the production of novel combinations, based here on meaning. Bybee and Eddington 2006 study verbs of becoming in several large Spanish corpora to determine which verbs go with which adjectives. This case is another one in which attempts to establish rules or ferret out the relevant features of the verbs and adjectives have not been successful. There are several verbs in Spanish that are used with adjectives or prepositional phrases to signal 'entering into a state'.
} 
Considera-se, dessa forma, uma relação estreita entre cognição, gramática e frequência de uso das formas linguísticas. Um bom exemplo para ilustrar é o caso da construção [um monte de $S N]$. Analisando dados de um monte de $S N$ na língua portuguesa, constata-se que a maioria dos usos correspondem a SNs com valores genéricos, a saber coisa(s) e gente. Esse resultado mostra que o uso impacta a representação cognitiva das formas linguísticas e que, de maneira análoga, a representação cognitiva da construção interfere no uso.

Fumaux (2018), fazendo uma análise diacrônica da formação da construção quantitativa binominal um monte de $S N$, demonstrou que os primeiros usos de um monte de $S N$ correspondem àqueles em que monte se refere a uma formação geológica, a partir de dois contextos principais: (i) casos como um monte de Atenas, remontando a um monte localizado em Atenas e tomando sua localização como ponto de referência para identificação do monte (exemplo 1 abaixo); (ii) exemplos como um monte de geada, em que metonimicamente se toma uma parte do monte, coberta sazonalmente por neve, como ponto de referência para identificação de todo o monte (exemplo 2).

(1 ) "Isto He suaue \& gostoso. Dir-se-a d as cousas de que gostarmos. Porque hymetos foy hum monte de athenas. Onde auia o melhor mel do mundo." (CORPUS DO PORTUGUÊS, Dicionário de Latim-Português 1 , séc. XVI)

(2) "E o termho d'Elvyra He muy avondado e ha hyhûû monte a que chama Xalayr. E tanto quer dizer Xalayr como monte de geada, por que em todo ho ano nûca se parte della a neve, ca tanto que se hûa neve parte logo a outra vem. E, quando vãã a este monte em tempo de caentura, acha hy mui saborosos logares pera folgar e muytas flores e muitas auguas de fontes e muitas especias que meten nas meezinhas.” (CORPUS DO PORTUGUÊS, Crônica Geral de Espanha, séc. XIV)

Dados desse tipo relacionam-se hierarquicamente na rede linguística a níveis construcionais mais abstratos, em que um monte de $S N$ é associado a uma construção mais geral [[SN] de SN] do esquema dos modificadores nominais da língua portuguesa. Como se viu, usos metonímicos (tal como um monte de geada) promovem uma relação em que uma parte do que o monte é feito (geada) é usada pra se referir ao monte inteiro. Usos mais periféricos dessa construção - um monte de corpos mortos, por exemplo, identificando um conjunto de corpos mortos empilhados - dão conta de associações metafóricas entre, novamente, a ideia de uma formação vertical (não mais o monte físico) e a referência a ela a partir de partes que a compõem - no caso, corpos mortos. 
Usos como esse são considerados mais periféricos e requerem uma operação cognitiva (no caso, a metáfora) para sua interpretação. O aumento de casos desse tipo, portanto, leva a uma inferência sugerida pelo contexto: para se ter uma pilha de corpos, é preciso mais de um corpo. Diferentemente do caso de geada, em que se falava de uma parte massiva do monte, as partes (corpos mortos) se configuram como unidades delimitadas e separadas fisicamente (para maiores esclarecimentos, conferir TALMY, 2006), as quais são interpretadas a partir de uma relação imagética de uma formação física ascendente (monte).

A inferência de mais de um (e o consequente mismatching, isto é, o desacordo semântico entre itens e construção) faz de exemplos como esses gatilhos para a mudança, já que a ideia de quantidade é implicada. Ocorre que, com o passar do tempo, exemplares gerando inferências de quantidade são cada vez mais frequentes e, em um dado momento (entre os séculos XVIII e XIX), a associação metafórica já não pode mais ser recuperada, como o que se pode ver em um monte de empresas, por exemplo. A alta frequência de exemplares fazendo uso de um monte de $S N$ para quantificar SN contáveis leva à associação de um monte de $S N$ a uma estrutura ascendente $(S N$ de $S N)$ quantificadora, ou seja, integrante do esquema de quantificadores e relacionada na rede a outras como: de um lado, uma cambada de SN, uma exurrada de SN etc.; de outro, a quantificadores como muito, pra caramba, etc.

A migração de um monte de $S N$ do esquema dos modificadores para o esquema dos quantificadores demonstra a relação de herança entre as duas construções [um [monte] de $\mathrm{SN}]_{\text {especif. }}$ e $[\mathrm{um} \text { monte de }[\mathrm{SN}]]_{\text {quantif. }}$ No que tange a essa relação, é possível dizer que, cognitivamente, formou-se um chunk na parte fixa da construção de função quantificadora (um monte de), que passou a valer como um quantificador - tome-se a comparação entre muitos livros e um monte de livros. A rede a seguir, adaptada de Fumaux (2018), ilustra a extensão de usos relacionados à construção de modificação até a formação de uma nova construção de quantificação na língua portuguesa: 


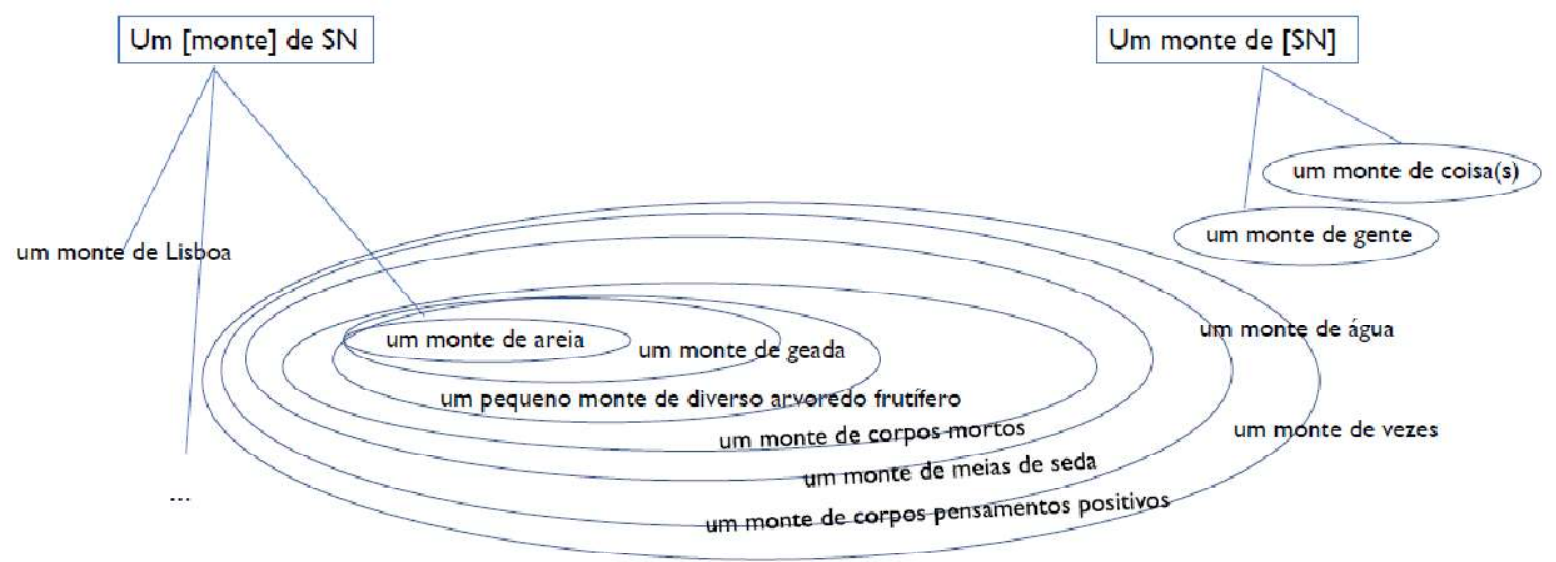

Figura 4: A rede linguística (fonte: FUMAUX, 2018, p. 99)

O mesmo acontece com um monte de gente, como no exemplo (3), em que a leitura de um monte de expressa quantidade:

(3) "Mas eu tenho dificuldade quando tem muita gente. Não consigo dar atenção pra um monte de gente ao mesmo tempo." (CORPUS DO PORTUGUÊS, séc. XX)

Sendo assim, assumimos que a formação de novas construções, dentro de um modelo baseado no uso, emerge de mudanças que afetam padrões construcionais gerados por exemplares menos coerentes em uma dada construção. Essas mudanças, que podem gerar construções polissêmicas bem como a formação de uma nova construção herdada da anterior (entende-se, proveniente de usos menos prototípicos da anterior) mostram que: (i) o locus da mudança linguística está no uso (TRAUGOTT \& TROUSDALE, 2013); (ii) a língua é uma rede de construções estruturadas - conforme já demonstrado na literatura e muito bem ilustrado por Goldberg (1995: p. 68) quando recupera a fábula de Borges "Funes, o Memorioso". Sendo a língua uma rede estruturada, assume-se que o conceito de herança é necessário e extensão e importante, pois está ligada a categorização, bem como a mudanças construcionais (TRAUGOTT \& TROUSDALE, 2013).

Dada a não-factualidade de uma língua formada por um emaranhado não relacionado de formas linguísticas, assume-se que a arquitetura gramatical de uma língua se forma tal como uma rede. A respeito dessa organização gramatical, postula-se que os falantes, diante da 
repetição de formas linguísticas, abstraem padrões de uso. Tomando um outro exemplo dentro do conjunto de construções quantitativas à guisa de ilustração, pode-se dizer que o uso repetitivo de uma cambada de ladrões no português leva ao entendimento de que existe uma forma de quantificar nomes que é composta por um artigo indefinido + o nome cambada + ladrões, num primeiro momento. Num segundo momento, a existência de outros exemplares, como uma cambada de idiotas, uma cambada de covardes, uma cambada de mentirosos, leva o falante a, analogicamente, associar esses usos e abstrair (categorizando os usos) um padrão mais geral (fruto de equivalências lexicais e estruturais) a partir daí - no caso, uma cambada de $S N$.

A repetição de usos categorizáveis sob a fórmula (estrutura esquemática) uma cambada de $S N$ leva este padrão a ser armazenado como um chunk, ou seja, como uma unidade cognitiva integrada, passando a ser representado na rede construcional como uma estrutura ascendente emergente da comparação de usos. Também analogicamente, o falante associa estrutural e funcionalmente uma construção do tipo uma cambada de $S N$ com outras como uma porrada de $S N$, um bando de $S N$, uma enxurrada de $S N$, uma série de $S N$ etc., emergindo daí uma estrutura esquemática ainda mais ascendente - SN de SN. Os mecanismos de associação e abstração representam, na abordagem baseada no uso, não apenas a forma como lidamos com unidades simbólicas de natureza linguística, mas sim um modelo de aprendizagem em âmbito mais geral.

Para tratar de herança e extensão das construções de uma língua sob a ótica dos Modelos Baseados no Uso, defendemos que exemplares mais periféricos de uma dada construção levam a inferências pragmáticas (invited inference, conforme TRAUGOTT \& DASHER, 2005) que, a um dado momento, podem promover o surgimento de um novo pareamento forma-sentido. De um lado, exemplares mais centrais de uma construção fortalecem na memória a parte mais fixa da construção (BYBEE, 2013) - por exemplo, uma enxurrada de; de outro, também reforçam uma função (sentido) a ela associada. Assim, exemplares cada vez mais distantes precisam cada vez mais se conformar ao sentido da construção e as operações cognitivas provenientes daí podem promover inferências advindas de associações a formas já disponíveis, incluindo aí a relação entre formas pertencentes a diferentes esquemas da língua (TRAUGOTT \& TROUSDALE, 2013). 


\section{Os níveis da construção e a formação de novas construções nas línguas}

Sendo a gramática de uma língua uma rede de construções conectadas e cada construção formada por um conjunto de propriedades da forma e do sentido (cf. figura 1), cabe-nos agora apresentar os níveis da construção, do constructo (uso) ao esquema e retomar a concepção de mudança apresentada por Traugott e Trousdale (2013).

Os níveis da construção, nessa concepção, são o esquema (construção esquemática), o subesquema (construção semiesquemática) e a microconstrução. As instanciações da microconstrução são os constructos. De acordo com Zhan \& Traugott (2015, p. 463), um dado conjunto de construções de uma língua pode ser distribuído de acordo com o nível de esquematicidade que tais construções apresentam:

a. Esquemas: construções abstratas que são generalizações taxonômicas sobre diversas construções mais particulares.

b. Subesquemas: subgrupos de esquemas, menos abstratos, mas ainda assim construções esquemáticas.

c. Microconstruções: construções do tipo individual. Membros de um subesquema pequeno.

d. Constructos: Instâncias de microconstruções, tokens de uso real.

Hilpert (2014) postula que fazem parte do conhecimento linguístico do falante as variações de forma e as variações de sentido (polissemia) de uma construção. Tudo é memorizado. É este o sentido de variação numa abordagem construcionista. Já a mudança, nesta perspectiva, está relacionada com o aumento ou diminuição do uso de uma das variantes (de forma e de sentido). Traugott e Trousdale (2013) postulam que a mudança linguística ocorre quando há alterações ou na forma ou no sentido e quando ocorre mudança nos dois planos ocorre construcionalização, ou seja, uma nova construção, um novo nó na rede. A nova construção estabelece links de herança com a construção de origem. Apresentamos a seguir uma figura para ilustrar tanto os níveis da construção como a construcionalização: 


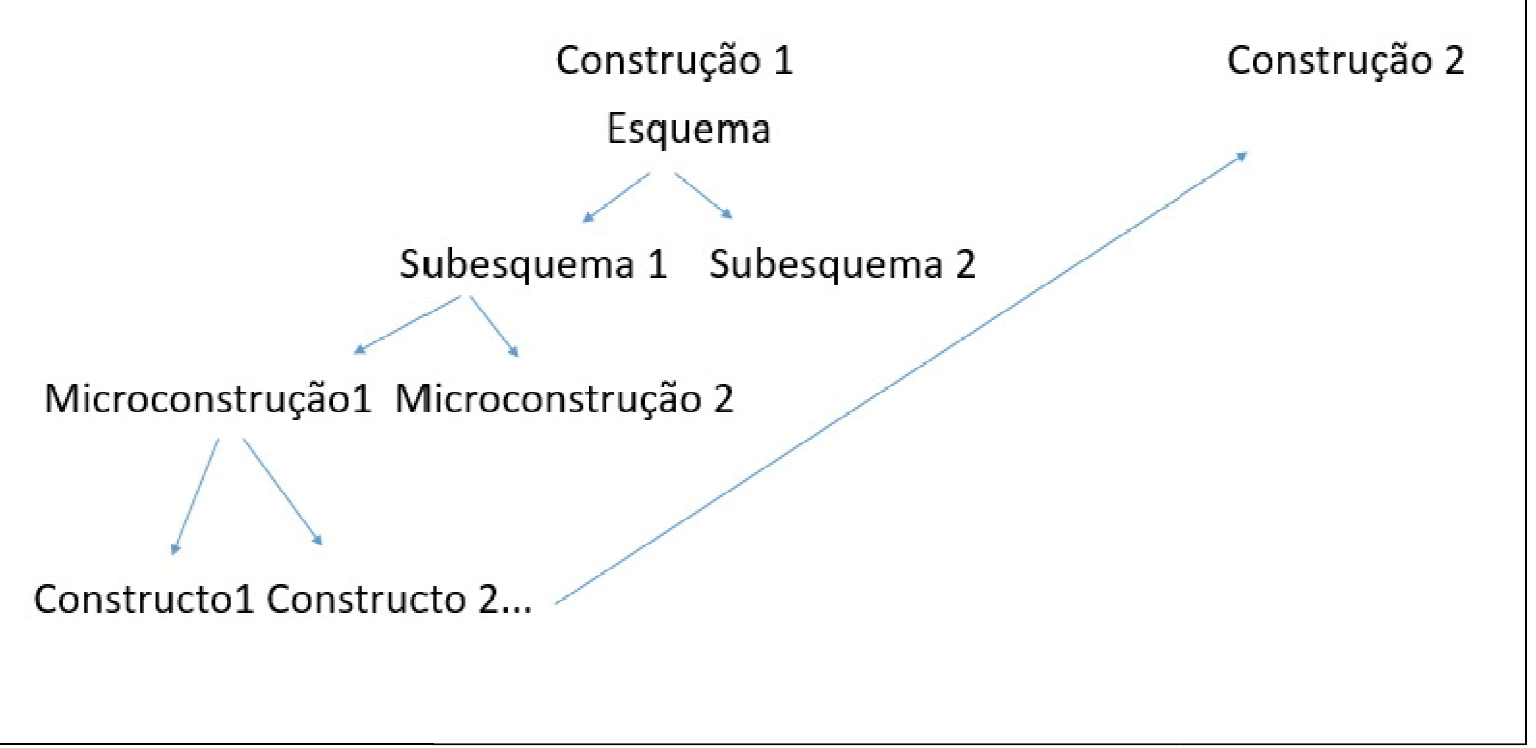

Figura 5: Níveis da construção e construcionalização.

Na história de uma língua, a repetição de usos linguísticos leva à formação de microconstruções, subesquemas e esquemas mais gerais; cada nível desses apresenta forma e sentido, sendo, portanto, pareamentos simbólicos forma-função (cf. figura 1). Pode haver mudança construcional em qualquer nível. Para haver construcionalização um dos usos de uma microconstrução sofre mudança na forma e no sentido, há convencionalização do uso e entrada na língua de uma nova construção (construção 2, na figura 5). Valeria destacar que essa construcionalização pode ocorrer no nível da construção.

Rosário e Teixeira (2016) propõem tratar de forma diferente a formação de microconstrução (microstrucionalização ou construcionalização propriamente dita) e a formação de esquema (esquematização) e de subesquema (subesquematização):

A emergência de novas microconstruções, subesquemas e esquemas, apesar de envolver diferentes processos, tem sido tratada indistintamente na bibliografia sob o rótulo geral de construcionalização. Essa questão não está devidamente sistematizada em Traugott e Trousdale (2013), mas, nessa obra, de forma esparsa, é possível detectar informações sobre a construcionalização de microconstruções (ou microconstrucionalização), construcionalização de subesquemas e construcionalização de esquemas. (ROSÁRIO e TEIXEIRA, 2016, p. 143) 
E ainda: “(...) propomos que o conceito de construcionalização seja reinterpretado, por meio da adoção de termos distintos que representem mais fielmente os diferentes processos aqui discutidos:

- Criação de novo esquema $\rightarrow$ Esquematização.

- Criação de novo subesquema $\rightarrow$ Subesquematização.

• Criação de nova microconstrução $\rightarrow$ Microconstrucionalização ou Construcionalização" (p. 148).

Ao nosso ver, essa forma de trabalho concebe que haja três tipos de mudanças, o que seria muito pouco econômico do ponto de vista teórico-metodológico e, mais importante, seria pouco econômico do ponto de vista cognitivo. Se é o uso e os processos cognitivos do domínio geral que criam uma microconstrução a partir de outra construção e se é o aumento de elementos de uma parte dessa microconstrução (aumento da classe hospedeira) que a levará a ficar mais esquemática, por que tratar as duas criações como dois processos e não apenas um processo? Ou seja, o processo de criação de pareamentos, mais ou menos esquemáticos ou substantivos. O processo é cíclico: dos usos de uma microconstrução pode haver aumento de esquematidade e se formar um pareamento com uma parte esquemática; depois de formada a construção mais esquemática, novas microconstruções podem ser instaciadas.

Concebemos que a formação tanto do esquema como da microconstrução como fases de um mesmo fenômeno. Quando os linguistas dos modelos baseados no uso propõem que se meça o grau de produtividade através da frequência tipo é exatamente para ver se já há esquematicidade, verificar que elementos se combinam com uma base, se há um elemento mais frequente que poderia ter dado o gatilho para a formação da construção mais abstrata, como ocorreu com crazy em X drive PRO Y. Tudo indica que foi o adjetivo crazy que serviu de gatilho para a formação da construção mais esquemática. Inicialmente havia duas possiblidades - crazy e mad - mas crazy era o mais frequente e podia ser usado metaforicamente. Com o tempo, outros elementos foram recrutados: up the wall, bananas. Pelo princípio da coersão, a construção é interpretada da mesma forma como se tivesse crazy no lugar do X (Cf. BYBEE, 2010). 
$\mathbf{O}$ caso de $\left[\mathbf{V A} \mathbf{A}_{\text {adv }}\right]_{Q u a l i t}$

Vejamos mais um exemplo de como se forma tanto um esquema como uma microconstrução através da formação do esquema $\left(\left[\mathrm{VA}_{\mathrm{adv}}\right)\right]_{\text {Qualit }}$ e de microconstruções que desse esquema se desgarraram e passaram para outro nó na rede. $\mathrm{O}$ esquema, com valor qualitativo (ou em outros termos, modal) é formado por um verbo mais adjetivo adverbial, como falar alto, bater forte.

Campos, Marques e Cezario (inédito) e Campos (2018) demonstram que os usos de diversos verbos com o modificador adjetivo adverbial criaram os subesquemas [falar $\left.\left[\mathrm{A}_{\text {adv }}\right]\right]_{\text {Qualit }},\left[\operatorname{cantar}\left[\mathrm{A}_{\mathrm{adv}}\right]\right]_{\text {Qualit, }},\left[\text { bater }\left[\mathrm{A}_{\mathrm{adv}}\right]\right]_{\text {Qualit, }}\left[\text { abraçar }\left[\mathrm{A}_{\mathrm{adv}}\right]\right]_{\text {Qualit, }}$ etc. Usos semelhantes a esses levaram à formação do esquema mais abstrato $\left[\mathrm{V} \mathrm{A}_{\mathrm{adv}}\right]_{\text {Qualit }}$ desde o latim vulgar. Desse esquema $\left[\mathrm{VA}_{\mathrm{adv}}\right]_{\text {Qualit, }}$ mais precisamente do subesquema $\left[\text { falar }\left[\mathrm{A}_{\mathrm{adv}}\right]\right]_{\text {Qualit }}$ e do subesquema

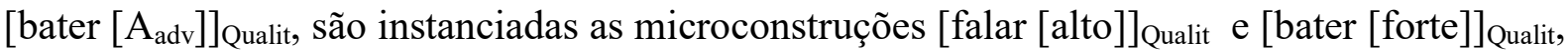
em que alto e forte têm valor de modo e os sentidos dos verbos são denotativos, como em (4) e (6). Campos (2018) observou que, de um total de 392 dados analisados em blogs do Corpus do Português, havia 106 itens verbais diferentes no slot $\mathrm{V}$ e desses verbos os mais frequentes eram falar e bater, totalizando $29 \%$ do total de dados coletados. O verbo falar é mais usado com $\mathrm{A}_{\mathrm{adv}}$ alto e o verbo bater, com o $\mathrm{A}_{a d v}$ forte. Tais dados ainda têm o $\mathrm{A}_{\mathrm{adv}}$ com o valor de modificador do verbo. A alta frequência desses usos levou ainda ao chunking dessas formas em um determinado uso. Falar alto e bater forte deixam de ser instanciações diretas do nó $\left[\mathrm{VA}_{\mathrm{adv}}\right]_{\text {Qualit }}$ e passam a ser construções lexicalicalizadas em (5) e (7).

(4) "Quando o nosso cérebro reconhece uma situação de perigo, o sistema nervoso simpático é ativado e libera substâncias chamadas adrenérgicas, que preparam o nosso corpo para reagir. É por isso o coração bate mais forte, bombeando mais sangue, as pupilas dilatam, ficamos mais alerta e os vasos se contraem" (ajudaemocional.tripod.com)

(5) "Essa questão do branqueamento bateu forte em mim e eu sei que bate muito forte em muitos negros também”. (amaivos.uol.com.br)

(6) Hoje me assusto quando vejo alguém, (são muitos que falam alto, nossos tímpanos quase estouram;) a menos valia do ser. Queremos ser ouvidos, vezes em conversas grupais se 


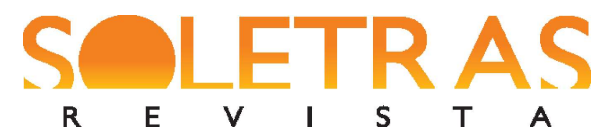

N.37 - 2019.1 - MARIA MAURA CEZARIO

KAREN SAMPAIO BRAGA ALONSO

perguntarmos o que cada um falou... difícil (http://anamgs.blogspot.com/2011/10/porque.html)

(7) "Não há milagres, a razão deve falar alto para que os ânimos não se exaltem" (http://amelhordasintencoes.wordpress.com)

Podemos ilustrar tanto os níveis da construção $\left(\left[\mathrm{VA}_{\mathrm{adv}}\right)\right]_{\text {Qualit. }}$ quanto a conexão com as duas construções substantivas falar alto e bater forte. Após a análise de diversos fatores, Campos (2019), ao estudar essas construções, resume num quadro como é a rede de $\left(\left[\mathrm{VA}_{\mathrm{adv}}\right)\right]_{\text {Qualit. }}$ e como surgiram as ovas construções lexicalizadas:

Como vemos, o uso criou a formação de esquemas e a frequência de algumas microconstruções levou a novas construções não esquemáticas. Não são, portanto, dois fenômenos: tanto a formação de esquemas como a formação de construções substantivas (ou seja, não esquemáticas) são resultados de generalizações feitas a partir da frequência de uso, neoanálises através de inferências, chunking, analogia e categorização.

\section{Considerações finais}

Concebemos que há vários níveis de abstração, desde a microconstrução até o esquema mais alto. A formação de uma microconstrução nova, portanto, está englobada entre os casos de construcionalização (porque é um novo pareamento forma-função), não havendo a necessidade, a nosso ver, de se propor um novo processo para dar conta desse nível. Com o tempo, a nova microconstrução pode sofrer aumento de produtividade e, em consequência, tornar-se mais esquemática, gerando slot aberto. As microconstruções podem ser instanciações da construção abstrata (antiga microconstrução substantiva, ou seja, menos esquemática) numa sincronia ou podem também ganhar um valor convencional novo e ter sua própria distribuição morfossintática. Neste último caso, dizemos que houve construcionalização.

Vemos vantagens em se conceber que a construcionalização abarque tanto a formação de novas microconstruções como a formação de construções mais esquemáticas: processos cognitivos de mesma ordem formam construções mais esquemáticas e microconstruções; o aumento de produtividade de um (medida sobretudo pela frequência de tipo) de um esquema 
e subesquema cria novas microconstruções, então microconstrução é uma fase da formação de esquemas e subesquemas; e a frequência de ocorrência (tokenfrequency) reforça a representatividade de uma forma tornando-a um novo paramento forma-função da língua.

A delimitação das unidades da língua como construtos (usos) e microconstruções é um dos grandes desafios que o modelo de análise nos lança, não há dúvidas. Inclusive porque nós, que trabalhamos com a teoria da construcionalização e das mudanças construcionais, basicamente observamos e analisamos mais detidamente o epifenômeno coletivo da estrutura sintática superficial de uma dada língua (a gramática da língua, e não do indivíduo), sem, muitas vezes, atrelar essa metodologia à realização de testes psicolinguísticos. O indivíduo, por outro lado, é uma grande potência armazenadora de construções, com uma memória de armazenamento de capacidade muito grande. A abrangência do que ele pode de fato vir a memorizar na sua gramática individual é um caminho bastante profícuo de investigação que vem contribuindo fortemente para o melhor entendimento da natureza do nosso conhecimento linguístico. Sequências como copo d'água, abrir a porta, chave do carro, por exemplo, são boas candidatas a construção, ou seja, são unidades potenciais automatizadas na língua, sendo potencial e psicologicamente reais.

No caso das construções [um monte de $\mathrm{SN}]$ e $\left[\left(\left[\mathrm{VA}_{\mathrm{adv}}\right)\right]_{\text {Qualit, }}\right.$ pudemos mostrar os níveis mais ou menos esquemáticos que tais construções instanciam e novas construções que são geradas ou por analogia (como uma cambada de $S N$, uma constelação de $S N$ ) ou pela fixação de dois lexemas com um valor menos composicional como as expressões falar alto e bater forte.

\section{Referências}

BARLOW, Michael., KEMMER, Suzanne. (Org.). Usage based models of language. Stanford, California: CSLI Publications, 2000.

BYBEE, Joan. Language, usage and cognition. Cambridge: Cambridge University Press, 2010 .

CAMPOS, Júlia Langerde, CEZARIO, Maria Maura and ALONSO, Karen Sampaio Braga. Formação da construção Xmente. DELTA, Mar 2017, vol.33, nº. 1, p.133-158. 
CAMPOS, Júlia Langer de, MARQUES, Priscilla Mouta; CEZARIO, Maria Maura. Construções adverbiais qualitativas em competição? Análise da relação entre as construções com adjetivo adverbial e com advérbio canônico no português brasileiro atual. Rio de Janeiro: UFRJ, inédito.

- Análise da construção [V AA] em variação com a construção [V Xmente] de pareamento qualitativo no PB. Rio de Janeiro: SEPLA-UFRJ, 2018. Versão impressa da apresentação.

. Competição entre [Verbo Adjetivo Adverbial] e [V mente] na rede construcional qualitativa do português brasileiro: uma análise centrada no uso. Rio de Janeiro: UFRJ/ Faculdade de Letras, 2019

CROFT, Willian. Radical Construction grammar: syntactic theory in typological perspective. Oxford: Oxford University Press, 2001.

DAVIES, M., FERREIRA, M. J. O corpus do português (45 milhões de palavras, sécs. XII$\mathrm{XX}$ ). 2006. Disponível em: <http://www.corpusdoportugues.org $>$. Último acesso em: $22 / 09 / 2018$.

DIESSEL, Holger. Usage-based construction grammar. In EwaDabrowska and Dagmar Divjak (Eds.), Handbook of Cognitive Linguistics, 295-321. Berlin: Mouton de Gruyter, 2015.

GOLDBERG, Adele Eva. A construction grammar approach to argument structure. Chicago/London: The University of Chicago Press, 1995.

Constructions at work: the nature of generalization in language. Oxford: Oxford University Press, 2006.

Constructionist approaches. In: Hoffmann and Trousdale. 2013. The Oxford Handbook of Construction Grammar. New York: Oxford University Press, 2013, p 13-51.

LANGACKER, Ronald. Foundations of cognitive grammar. Stanford: Stanford University Press, 1987. 2v.

MARQUES, Priscilla, ALONSO, Karen \& PINHEIRO, Diogo. 2017. Do signo à construção: o legado saussuriano e as abordagens construcionistas da gramática. Revista Gragoatá. Revista dos Programas de Pós0graduação do Instituto de Letras da UFF. Volume 22, n. 44, 2017, p. 1149-1171.

SAUSSURE, F. Curso de Linguística geral. São Paulo: Cultrix, 2006.

TEIXEIRA, Ana Cláudia Machado; ROSÁRIO, Ivo da Costa do. O estatuto da microconstrucionalização no quadro da mudança linguística. Revista LinguíStica / Revista do Programa de Pós-Graduação em Linguística da Universidade Federal do Rio de Janeiro. Volume Especial, dez de 2016, p. 139-151. 
TRAUGOTT, Elizabeth Closs, \& TROUSDALE, Graemer. Construcionalization and Constructional Changes. Oxford: University Press, 2013.

TRAUGOTT, E. \& DASHER, R. Regularity in Semantic Change. Cambridge: Cambridge University Press, 2006.

TRAUGOTT, E. C. Toward a coherent account of grammatical constructionalization. In: Jóhanna Bar dal; Elena Smirnova; Lotte Sommerer; Spike Gildea. (Org.). Diachronic Construction Grammar. 1 ed Amsterdam: John Benjamins Publishing Company, 2015.

ZHAN, F. \& TRAUGOTT, E. C. The constructionalization of the Chinese cleft construction. In: Studies in Language. N. 39. John Benjamins Publishing Company, 2015.

\title{
The Contribution of the Constructionalization and Constructional Changes approach to language change: reflexions on Portuguese Language
}

\begin{abstract}
In this paper, we will discuss Constructionalization/ Constructional Changes approach to language change proposed by Traugott and Trousdale (2013) from the way we have been working on constructions, constructional levels, constructional changes, formation of new constructions, etc. We will take two examples of researches supervised by us: one concerned to usages of [um monte de [NP]] (lit. a heap of NP/ 'a lot of NP'), and another one about the usages of $\left(\left[\mathrm{VA}_{\mathrm{adv}}\right)\right]_{\text {Qualit }}$ (Verb Adverbial Adjective with a modal value). We assume that grammar is formed by a network of connected constructions, and the formation of a construction occurs through the actuation of domaingeneral cognitive processes and routinization of certain uses due mainly to the high frequency of certain combinations of linguistic elements. We will show that, in current Portuguese, [Um monte de $\mathrm{NP}$ ] has a quantitative value and this value comes from a construction in which the prepositional phrase specifies the noun monte 'heap'. We will also illustrate the discussion with the case of the formation of idiomatic expressions (lexicalized constructions) from the more general construction $\left(\left[\mathrm{VA}_{\mathrm{adv}}\right)\right]_{\text {Qualit. }}$
\end{abstract}

Keywords: grammar as construction network; language change; formation of Portuguese constructions; constructionalization.

Recebido em: 23 de novembro de 2018 .

Aceito em: 29 de março de 2019. 